\title{
GEOMETRIC STRUCTURE OF THE C45 STEEL SURFACE AFTER CENTRIFUGAL BURNISHING AND PERPENDICULAR SHOT PEENING
}

\section{Agnieszka Skoczylas ${ }^{1}$}

${ }^{1}$ Lublin University of Technology, Nadbystrzycka 36, 20-618 Lublin, Poland, e-mail: a.skoczylas@pollub.pl

Received: 2017.07 .12

Accepted: 2018.04.04

Published: 2018.06.01

\begin{abstract}
The paper presents the research results of roughness and surface topography of the C45 non-alloy steel after centrifugal burnishing and perpendicular peening. The assessment of the geometric structure of the tested steel surface included the parameters: amplitude: Ra, horizontal: RSm, height: Rz, Rp and Rv, and Abbott-Firestone curve: Rpk, Rk and Rvk. Perpendicular shot peening was performed on a special position, while centrifugal burnishing on a 3 -axis milling centre $\mathrm{XH} 712 \mathrm{G}$. The variable parameters during shot peening included the impact energy $\mathrm{E}_{\mathrm{z}}=40 \div 220 \mathrm{~mJ}$ and the distance between traces $\mathrm{x}_{\mathrm{s}}=0,15 \div 0,5 \mathrm{~mm}$. The machining conditions of centrifugal burnishing were selected in such a way that the perpendicular component of the impact energy, longitudinal feed and transverse travel correspond to the variable parameters of perpendicular shot peening. The T800 RC 120 -140 device of the Hommel - Etamic company with software was used for measuring surface roughness and topography.
\end{abstract}

Keywords: centrifugal burnishing, perpendicular shot peening, surface roughness, surface topography.

\section{INTRODUCTION}

According to [19], the surface geometric structure (SGS) is a system of geometrical surfaces formed in the technological process of product manufacturing or in the manufacturing and using process. The geometrical structure of the surface includes roughness, waves, surface defects, sometimes shape errors [19].

The usability features of machine parts depend on the geometric structure of the surface. Resistance to abrasion, susceptibility to transfer of fixed or changing loads, corrosion resistance and fatigue strength depend on the surface roughness. Wave is a concentration place of stresses, which can lead to the formation of cracks [4]. The geometrical structure of the surface and its properties are determined by the type of machining.

Burnishing is one of the methods of finishing treatment, during which the local plastic deformation phenomenon is used for the surface layer, caused by the impact of a hard tool on the surface.
Due to the nature of the force applied during burnishing, the static burnishing and dynamic burnishing can be distinguished. The basic types of dynamic burnishing include centrifugal burnishing and shot peening [11].

During dynamic burnishing, prints (traces) are formed on the processed surface as a result of the impact of burnishing elements, which shape and dimensions depend on the properties of the workpiece, its roughness, the diameter of the burnishing element and the impact energy [3]. The resulting geometric structure of the surface resulting from the dynamic burnishing treatment is the result of complex processes, such as "punching" the indentations, levelling the micro-elevations formed in the earlier phases of burnishing, and the increasing surface layer hardness resulting from the density of the impact tracks $[11,16]$.

The surfaces treated by dynamic burnishing are characterised by high smoothness and high material bearing, which is related to the shape of micro-irregularities, which is more "streamlined" 
Table 1. The chemical composition and selected properties of non - alloy C45 steel

\begin{tabular}{|c|c|c|c|c|c|c|c|c|}
\hline \multicolumn{8}{|c|}{ Chemical composition (average), [\%] } \\
\hline $\mathrm{C}$ & $\mathrm{Mn}$ & $\mathrm{Si}$ & $\mathrm{P}$ & $\mathrm{S}$ & $\mathrm{Cr}$ & $\mathrm{Ni}$ & $\mathrm{Mo}$ & $\mathrm{Fe}$ \\
\hline 0,48 & 0,74 & 0,36 & 0,011 & 0,01 & 0,09 & 0,02 & 0,002 & rest \\
\hline \multicolumn{3}{|c|}{ Yield point (min.) } & \multicolumn{3}{c|}{$\mathrm{Re}=430 \mathrm{MPa}=740 \mathrm{MPa}$} \\
\hline \\
Tensile strength (min.) \\
\hline
\end{tabular}

$[8,10]$. "Punching" the machined traces on the processed surface allows the formation of potential "reservoirs" that can accumulate lubricants in their space, thereby contribute to increasing the wear resistance of these surfaces $[5,6]$. The geometric structure formed during processing affects the energy state and adhesion properties of the surface [12].

The impact effect of the tool on the workpiece also affects the physical properties of the surface layer. As a result of burnishing, the compressive stresses are constituted in the surface layer, this is a result of change of the structure defects concentration due to the performed machining [18]. There is also an increase of the surface layer micro-hardness due to burnishing [14]. The increased abrasion and fatigue resistance is the consequence of the change in the state of internal stresses and micro-hardness $[9,17]$.

The stereometric properties of the surface layer are formed by the centrifugal burnishing depend on: the magnitude of changes of the tool's traverse to the workpiece, peripheral speed of the burnishing head, the number of tool passages, the dimensions of the burnishing elements, the type of workpiece and the starting roughness of the workpiece [11].

The surface roughness after shot peening is dependent on the degree of coverage, the diameter of the peening balls, the type of material, from which the balls are made, the treatment duration and the impact energy $[1,2,7,13]$.

After a review of the literature, it can be stated that there are works on the centrifugal burnishing and shot peening. However, these studies refer to stereometric and physical properties of the surface layer for one particular variety of burnishing. There are no works that present a comparison of the stereometric properties of the surface layer after shot peening and centrifugal burnishing. Therefore, it was considered reasonable to undertake studies to compare the effect of technological parameters and burnishing variations on the geometric structure of the non-alloy steel elements surface. The selection of two types of dynamic burnishing, centrifugal burnishing and shot peening, was related to the machining capabilities of each of these variants and their advantages [12].

The assessment of the geometric structure of the surface was carried out based on the amplitude, horizontal, height and Abbott-Firestone curve parameters.

\section{RESEARCH METHODOLOGY}

The rectangular samples with the dimensions of $4 \mathrm{~mm} \times 15 \mathrm{~mm} \times 100 \mathrm{~mm}$, made of non-alloy C45 steel samples (marked according to PN - EN $10083-1: 2008)$ were used in the research. The grade of this steel is commonly used in the machine industry for medium-loaded components of machinery and equipment, such as: spindles, axles, non-tempered gear, discs, levers, wheel hubs. Table 1 presents the chemical composition and the selected properties of steel used in the studies.

Perpendicular shot peening was performed in a special position, which detailed description and principle of operation is presented in paper [16]. The machining was performed for variable technological parameters, which were, the impact energy $E_{z}$ and the distance between machining traces $\mathrm{x}_{\mathrm{s}}$, which values are illustrated in Table 2. During shot peening, the burnishing elements with the diameter of $\mathrm{d}_{\mathrm{k}}=6 \mathrm{~mm}$ was used.

Centrifugal burnishing was performed on the vertical 3-axis milling centre $\mathrm{XH} 712 \mathrm{G}$. The tool used for the machining was a special burnishing head with an external diameter of $70 \mathrm{~mm}$, which had symmetrically spaced burnishing beads with a diameter of approximately $6 \mathrm{~mm}$, in the amount of $\mathrm{z}_{\mathrm{k}}=12$. The variable parameters during machining included the peripheral speed of the head $\mathrm{v}_{\mathrm{g}}$, feed rate $v_{f}$ and the transverse feed $f_{p}$ (Table 2 ). The conditions for centrifugal burnishing were selected in such a way that the perpendicular component of diagonal impact energy corresponded to the beater impact energy with the sample surface during 
Table 2. Set of technological parameters used in burnishing tests

\begin{tabular}{|c|c|c|c|c|c|c|}
\hline \multicolumn{3}{|c|}{ PERPENDICULAR SHOT PEENING } & \multicolumn{4}{|c|}{ CENTRIFUGAL BURNISHING } \\
\hline Lp. & Impact energy $E_{z}[\mathrm{~mJ}]$ & $\mathrm{x}_{\mathrm{s}}[\mathrm{mm}]$ & $\mathrm{v}_{\mathrm{g}}[\mathrm{m} / \mathrm{min}]$ & $v_{f}[\mathrm{~mm} / \mathrm{min}]$ & $\mathrm{f}_{\mathrm{p}}[\mathrm{mm}]$ & $\begin{array}{c}\text { Traverse } \\
\text {-e [mm] }\end{array}$ \\
\hline 1 & 40 & \multirow{4}{*}{0,3} & 417 & \multirow{4}{*}{13640} & \multirow{4}{*}{0,3} & \multirow{7}{*}{0,5} \\
\hline 2 & 100 & & 659 & & & \\
\hline 3 & 160 & & 833 & & & \\
\hline 4 & 220 & & 977 & & & \\
\hline 5 & \multirow{3}{*}{160} & 0,15 & \multirow{3}{*}{833} & 6820 & 0,15 & \\
\hline 6 & & 0,4 & & 18187 & 0,4 & \\
\hline 7 & & 0,5 & & 22734 & 0,5 & \\
\hline
\end{tabular}

perpendicular shot peening. The calculations were performed on the basis of relationships presented in the publication [11]. The value of longitudinal feed $f_{w}$ and the transverse feed $f_{p}$ corresponded to the distance values between the traces $\mathrm{x}_{\mathrm{s}}$.

The evaluation of the geometrical structure of the surface after centrifugal burnishing and perpendicular shot peening was performed using the T8000RC 120 - 140 device of the HommelEtamic company, which allows for measurements of roughness and topography of the surface.

The studies also used the 3D digital microscope from the VHX - 500 series of the Keyence company, equipped with a digital camera with the capability of enlarging the analysed image from 100 to 1000 times.

\section{RESEARCH RESULTS}

The implementation of the research allowed the presentation of the influence of the variation of burnishing and technological parameters on the surface roughness, which was described using amplitude, height, horizontal and Abbot-Firestone curve parameters. The curve parameters of the material bearing are functional parameters and allow the prediction of how the given surface will behave in conjunction with another surface [15].

Surface roughness before perpendicular shot peening and centrifugal burnishing, which was milling, is in the range $\mathrm{Ra}=1,01 \pm 0,05 \mu \mathrm{m}, \mathrm{Rz}=$ $6,25 \pm 0,48 \mu \mathrm{m}, \mathrm{Rp}=4,62 \pm 0,46 \mu \mathrm{m}, \mathrm{Rv}=2,36$ $\pm 0,14 \mu \mathrm{m}, \mathrm{Rpk}=1,75 \pm 0,29 \mu \mathrm{m}, \mathrm{Rk}=3,25 \pm$

Table 3. Surface Topography (a), surface profile (b) and Abbott - Firestone'a curve for sample after milling

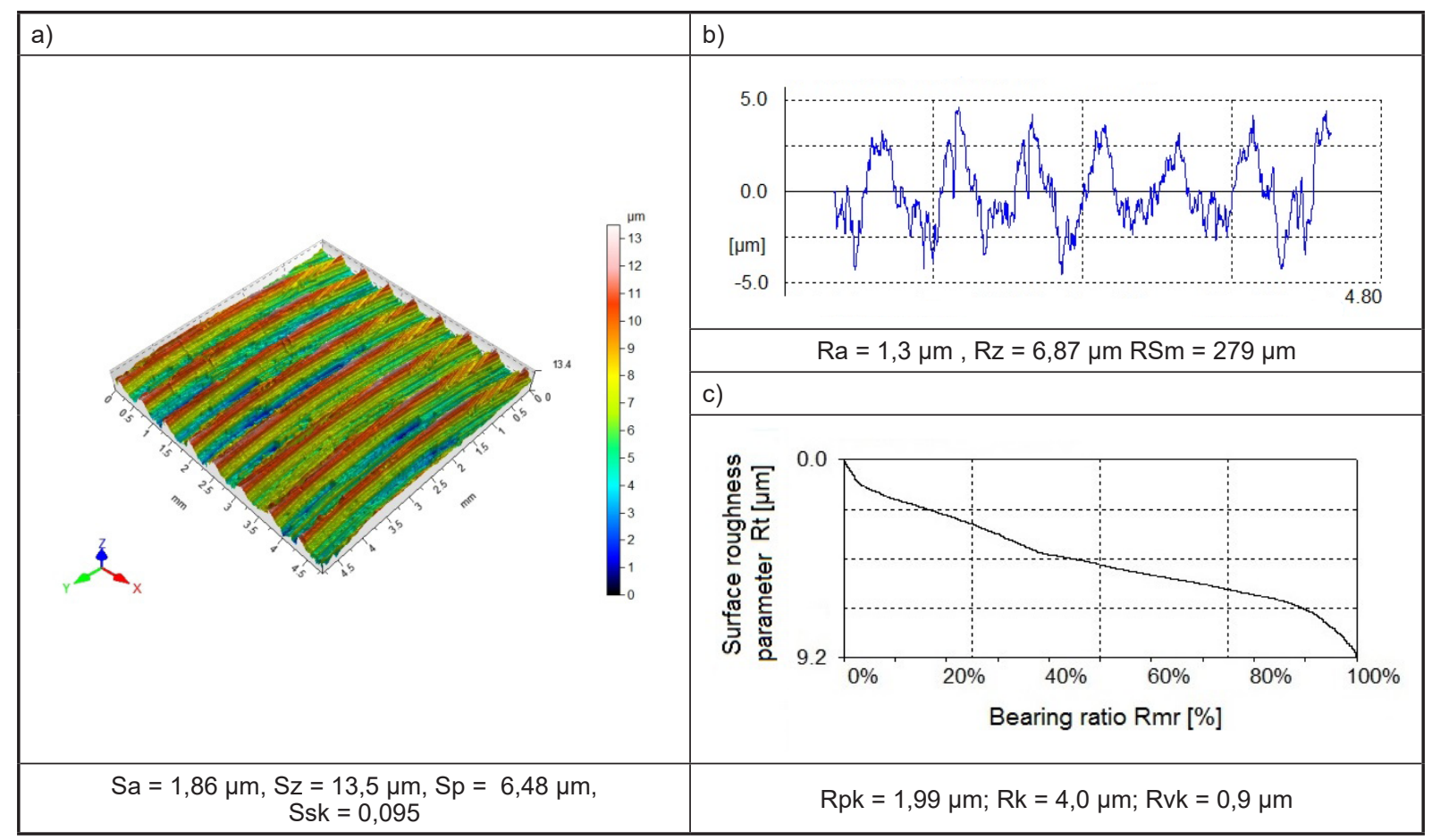




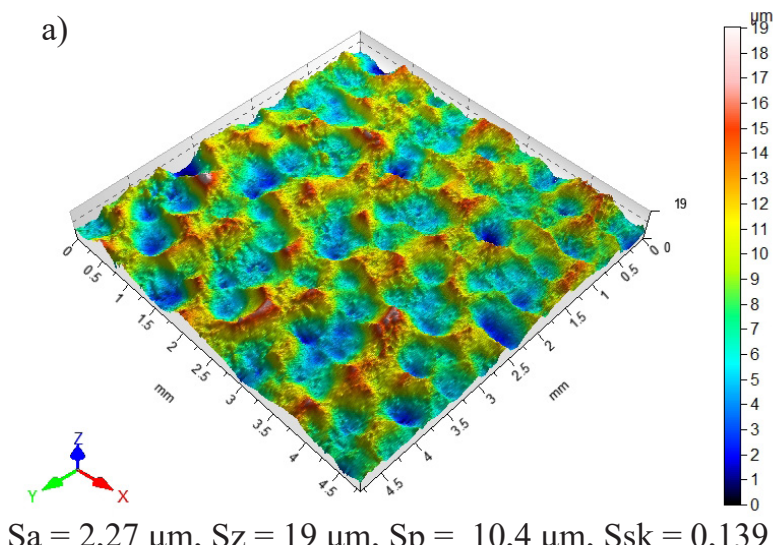

$\mathrm{Sa}=2,27 \mu \mathrm{m}, \mathrm{Sz}=19 \mu \mathrm{m}, \mathrm{Sp}=10,4 \mu \mathrm{m}, \mathrm{Ssk}=0,139$

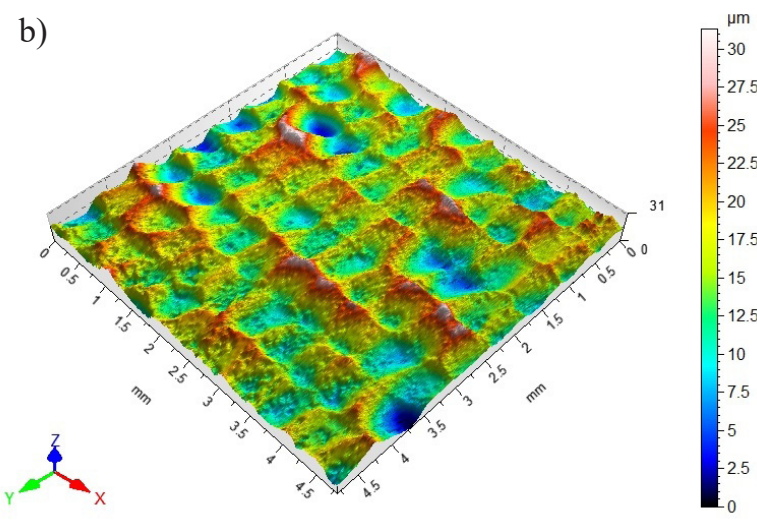

$\mathrm{Sa}=3,51 \mu \mathrm{m}, \mathrm{Sz}=31,3 \mu \mathrm{m}, \mathrm{Sp}=15,2 \mu \mathrm{m}, \mathrm{Ssk}=3,08$

Fig. 1. Topoghrapy of C45 surface after: a) centrifugal burnishing $\left(v_{g}=833 \mathrm{~m} / \mathrm{min}, v_{\mathrm{f}}=22734 \mathrm{~mm} / \mathrm{min}, \mathrm{f}_{\mathrm{p}}=0,5\right.$ $\mathrm{mm}), \mathrm{b})$ perpendicular shot peening $\left(\mathrm{E}_{\mathrm{z}}=160 \mathrm{~mJ}, \mathrm{x}_{\mathrm{s}}=0,5 \mathrm{~mm}\right)$

$0,18 \mu \mathrm{m}, \mathrm{Rvk}=1,47 \pm 0,23 \mu \mathrm{m}$ and $\mathrm{RSm}=0,263$ $\pm 0,026 \mathrm{~mm}$. On the surface of the workpiece the unidirectional array of micro-irregularities with equal spacing can be observed (Table 3a). The surface profile is characterised by sharp hills and dents (Table $3 b$ ). The material bearing curve is a degressive curve (Table 3c).

Figure 1 shows the surface topography after centrifugal burnishing and perpendicular shot peening. As a result of the machining, in both cases, the geometrical structure of the surface is rebuilt. After shot peening (Fig. 1b) the hollows are formed on the surface, which result from the impacts of the ball moving perpendicularly to the workpiece surface. The shape of the resulting traces is spherical, similar to the shape of the burnishing element. The machining traces are evenly distributed on the burnished surface. After centrifugal burnishing, the resulting traces are "pulled out", their shape resembles an ellipsis, their arrangement on the surface is not ordered. This is most likely due to the direction of impact of the spheres on the surface of the workpiece, this is the tangential direction.

The photos shown in Figure $2 \mathrm{a}$ and $2 \mathrm{~b}$ are the confirmation of the hypothesis about the influence of the direction of the spheres on the shape and distribution of the machining traces. For the sample subjected to perpendicular shot peening, the clear "concavities" can be seen on the surface and the shape of the impression is spherical (Fig. 2b). After centrifugal burnishing (Fig. 2a), a different shape of the workpiece has been obtained than in the case of perpendicular shot peening, of an elliptical shape.

The increase of the impact energy in the range of $\mathrm{E}_{\mathrm{z}}=40 \mathrm{~mJ} \div 160 \mathrm{~mJ}$ in the perpendicular peen-

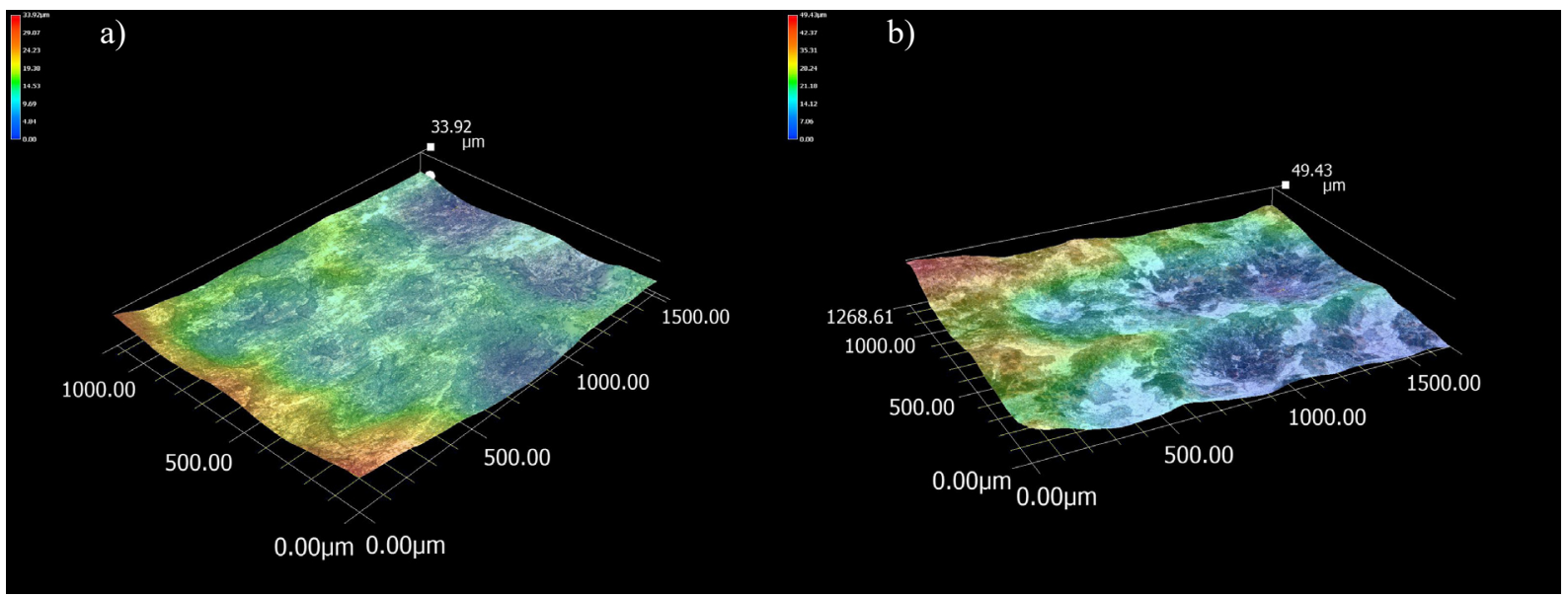

Fig. 2. The shape of the machining traces on surface $C 45$ steel: a) centrifugal burnishing $\left(\mathrm{v}_{\mathrm{g}}=833 \mathrm{~m} / \mathrm{min}, \mathrm{v}_{\mathrm{f}}=\right.$ $\left.\left.22734 \mathrm{~mm} / \mathrm{min}, \mathrm{f}_{\mathrm{p}}=0,5 \mathrm{~mm}\right), \mathrm{b}\right)$ perpendicular shot peening $\left(\mathrm{E}_{\mathrm{z}}=160 \mathrm{~mJ}, \mathrm{x}_{\mathrm{s}}=0,5 \mathrm{~mm}\right)$ 


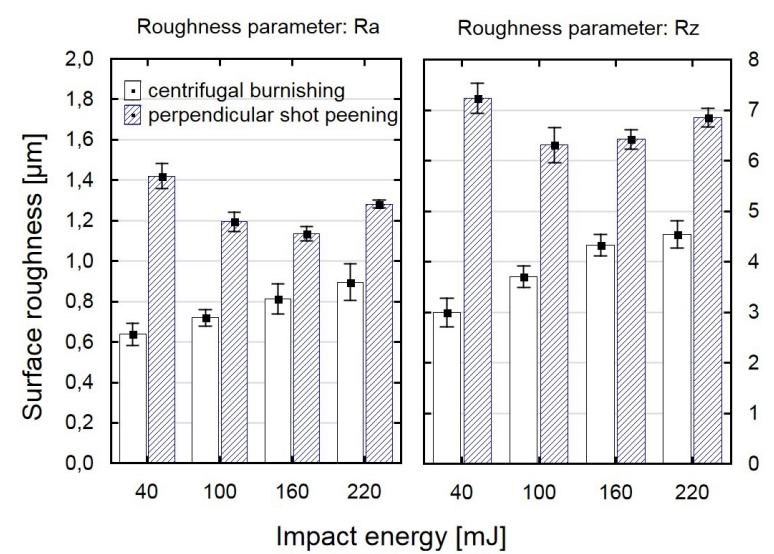

Fig. 3. Effect of impact energy on the surface roughness parameters $\mathrm{Ra}$ and $\mathrm{Rz}\left(\mathrm{x}_{\mathrm{s}}=0,3 \mathrm{~mm}, \mathrm{~d}_{\mathrm{k}}=6 \mathrm{~mm}\right)$

ing process at first causes the drop of roughness parameters $\mathrm{Ra}$ and $\mathrm{Rz}$ to the minimal value achieved for $\mathrm{E}_{\mathrm{z}}=160 \mathrm{~mJ}$, while in the range of $\mathrm{E}_{\mathrm{z}}=160 \mathrm{~mJ}$ $\div 220 \mathrm{~mJ}$ the surface roughness increases (Fig. 3). Applying the impact energy higher than $160 \mathrm{~mJ}$ causes the "punching" of greater indentations on the workpiece surface. In case of post-centrifugal burnishing samples, the surface roughness increases along with the impact energy. With regard to the values of $\mathrm{Ra}$ and $\mathrm{Rz}$ parameters before the treatment, within the applied impact energy scope, the improvement of the surface roughness takes place after centrifugal burnishing, while after perpendicular shot peening there is a slight deterioration of the surface quality.

The cyclical impact of the burnishing element, with the increasing impact energy, into the work surface causes the crushing of micro-irregularities vertices, which results in the reduction of the $\mathrm{Rp}$ and $\mathrm{Rpk}$ parameter values in case of

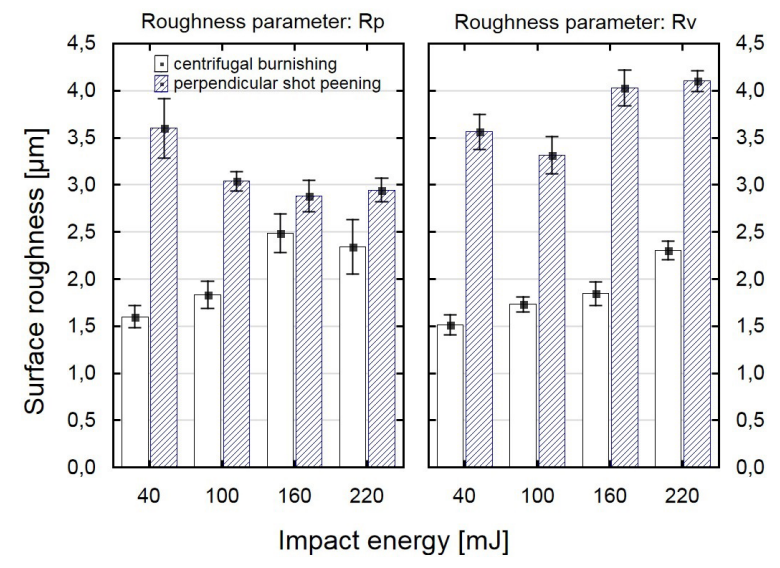

Fig. 4. Effect of impact energy on the surface roughness parameters $\operatorname{Rp}$ and $\mathrm{Rv}\left(\mathrm{x}_{\mathrm{s}}=0,3 \mathrm{~mm}, \mathrm{~d}_{\mathrm{k}}=6 \mathrm{~mm}\right)$

perpendicular shot peening machining (Figs. 4 and 5). The minimum value of the Rp and Rpk parameter was achieved for the energy equal $\mathrm{E}_{z}$ $=100 \mathrm{~mJ}$. The increase in the peripheral speed of the burnishing head, and thus the impact energy, results in the increase of Rpk and Rp parameters. The effect of perpendicular shot peening and centrifugal burnishing treatment is the formation of cavities on the work surface, which contributes to the increase in Rvk parameter, thus increasing the retention capacity of the lubricant (Fig. 5).

The surface after perpendicular shot peening is characterised by a profile with high height differences. The surface profile is described with flattened vertices. The $\mathrm{Rp}$ parameter after shot peening is from $22 \%$ to $38 \%$ smaller with respect to the value after pre-treatment, while Rv is higher from $51 \%$ to $71 \%$. Machining with centrifugal burnishing results in more intense abrasion of vertices of micro-irregularities. The height parame-
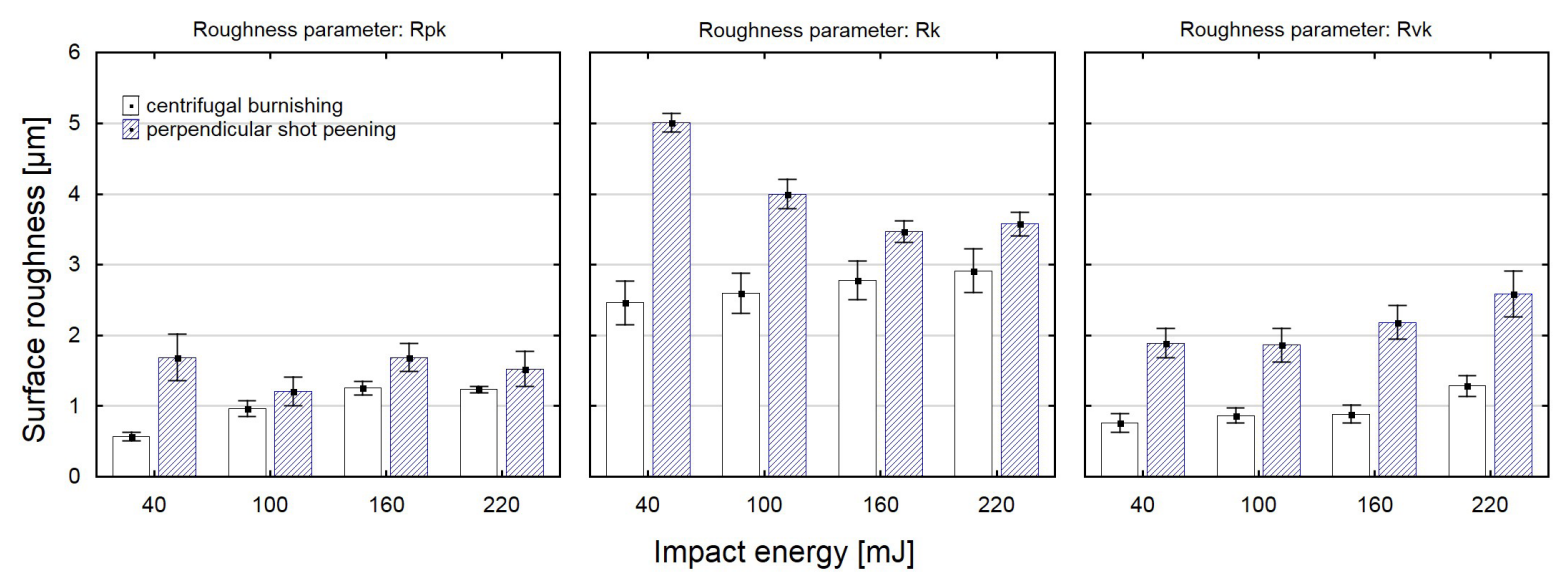

Fig. 5. Effect of impact energy on the parameters Abbotta - Firestone'a curve $\left(\mathrm{x}_{\mathrm{s}}=0,3 \mathrm{~mm}, \mathrm{~d}_{\mathrm{k}}=6 \mathrm{~mm}\right)$ 


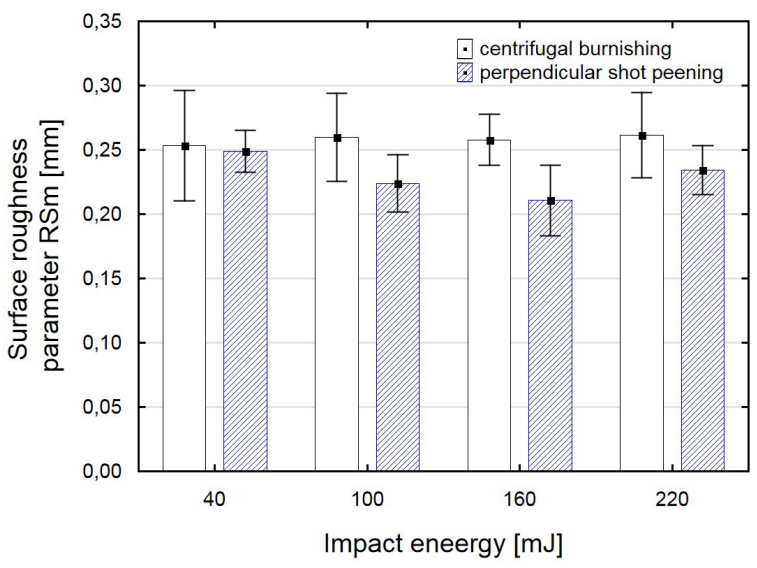

Fig. 6. Effect of impact energy on the surface roughness parameter $\operatorname{RSm}\left(\mathrm{x}_{\mathrm{s}}=0,3 \mathrm{~mm}, \mathrm{~d}_{\mathrm{k}}=6 \mathrm{~mm}\right)$

ter Rp after centrifugal burnishing is from 1,86 to 2,89 times smaller than after milling. This means the possible increase in abrasion resistance.

Figure 6 shows the effect of the impact energy on the roughness parameter RSm. The increase in impact energy does not cause significant changes in the spacing between micro-irregularities. The RSm parameter value after centrifugal burnishing oscillates around the value $\mathrm{RSm}=0,260 \mathrm{~mm}$, while after perpendicular shot peening it changes to a small extent.

Figures $7-9$ illustrate the effect of the distance between traces on the analysed surface roughness parameters. The increase in the distance between the machining tracks results in a reduction in the degree of coverage, and thus the uneven deformation of the processed surface. The surface roughness increases with respect to the pre-treatment during perpendicular schot peening for $\mathrm{x}_{\mathrm{s}}=0,3 \div 0,5 \mathrm{~mm}$, while for centrifugal burnishing the roughness parameters $\mathrm{Ra}$ and $\mathrm{Rz}$ are smaller than after milling in the entire range of the applied distance between traces.

Reducing the number of traces per surface unit leads to a lower proportion of plastic and elastic deformations, which increases the $\mathrm{Rp}$ and $\mathrm{Rv}$ parameters (Fig. 8). Changes in roughness parameters $\mathrm{Rp}$ and Rv are more noticeable in the case of the surface treated with perpendicular shot peening. This implies that the surface treated by peening is more "deformed" than after centrifugal burnishing.

The effect of the distance between the traces on the parameters of Abbott-Firestone curve (Fig. 9) is similar to the Ra, Rz, Rp and Rv parameters. The functional parameters after centrifugal burnishing have lower values than after perpen-

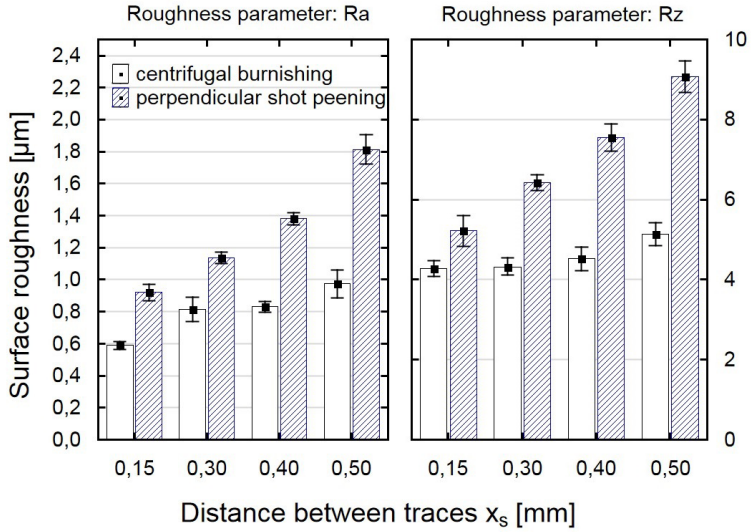

Fig. 7. Effect of distance between traces on the surface roughness parameters $\mathrm{Ra} i \mathrm{Rz}\left(\mathrm{E}_{\mathrm{z}}=160 \mathrm{~mJ}\right.$, $\left.\mathrm{d}_{\mathrm{k}}=6 \mathrm{~mm}\right)$

dicular shot peening. During centrifugal burnishing there is a phenomenon of "slipping" of the spheres on the surface, which probably results in a lower proportion of plastic and elastic deformations. The depth of roughness core Rk after centrifugal burnishing, in relation to the value after milling, is smaller from $2 \%$ to $44 \%$, while perpendicular shot peening causes the increase of the roughness parameter Rk. This means that centrifugal burnishing improves the so-called surface load, meaning that after the reaching period a part greater part of the surface will contact the surface of the co-operating element than after shot peening. During perpendicular shot peening, lubricated pockets are formed on the processed surface, the Rvk parameter after processing is from 1,15 to 1,75 times greater than after milling.

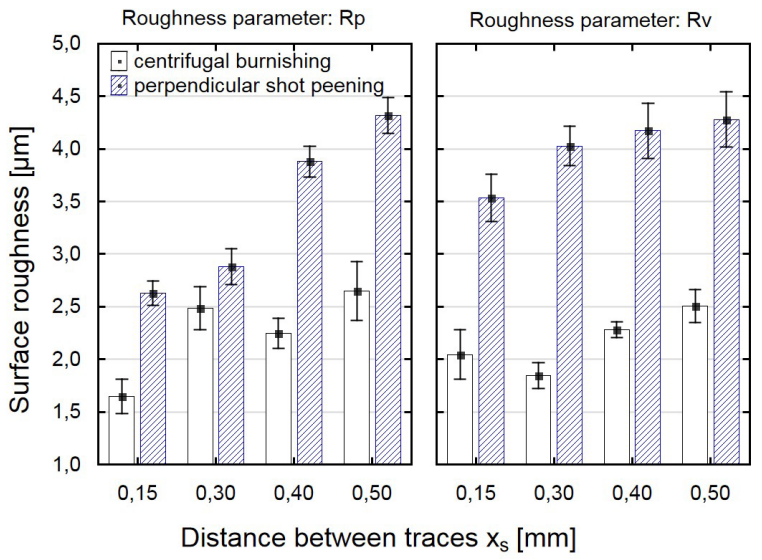

Fig. 8. Effect of distance between traces on the surface roughness parameters $\mathrm{Rp}$ i $\mathrm{Rv}\left(\mathrm{E}_{\mathrm{z}}=160 \mathrm{~mJ}\right.$, $\mathrm{d}_{\mathrm{k}}=6 \mathrm{~mm}$ ) 

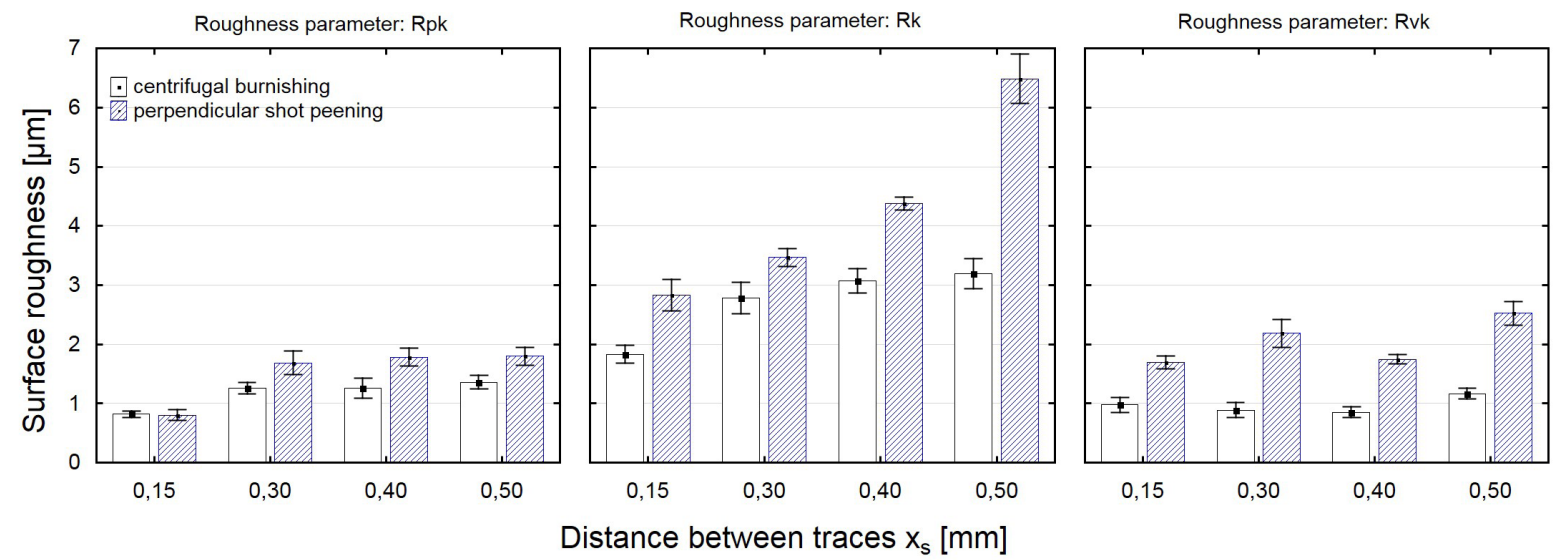

Fig. 9. Effect of distance between traces on the parameters Abbotta - Firestone'a curve ( $\left.E_{z}=160 \mathrm{~mJ}, d_{k}=6 \mathrm{~mm}\right)$

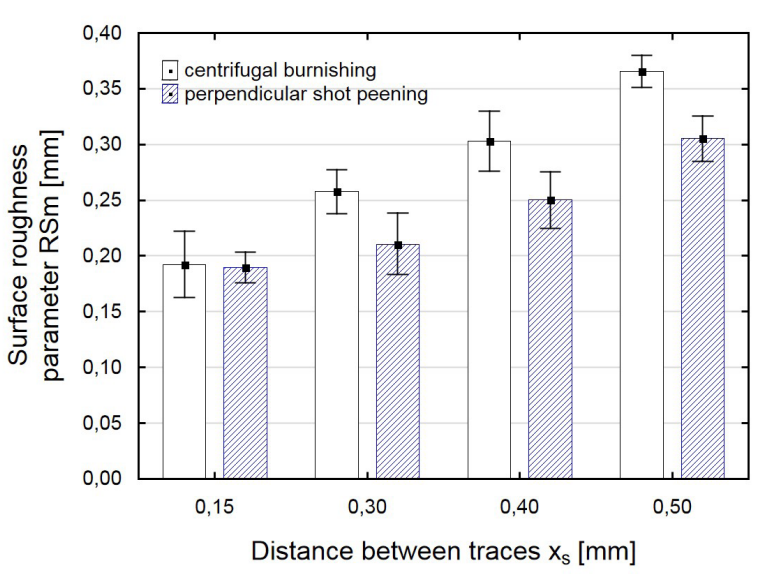

Fig. 10. Effect of distance between traces on the surface roughness parameter $\mathrm{RSm}\left(\mathrm{E}_{\mathrm{z}}=160 \mathrm{~mJ}\right.$,

$$
\left.\mathrm{d}_{\mathrm{k}}=6 \mathrm{~mm}\right)
$$

The distance between the micro-irregularities (parameter RSm) is impacted not only by the distance between the imprint traces, but also by the type of machining (Fig. 10). After centrifugal burnishing, micro-irregularities appear on the surface characterised by greater spacing. This is probably due to the shape of the resulting print. Greater changes in the RSm parameter value, depending on the variety of burnishing, can be observed for $\mathrm{x}_{\mathrm{s}}=0,3 \div 0,5 \mathrm{~mm}$. For the treatment with spacing $\mathrm{x}_{\mathrm{s}}=0,15 \mathrm{~mm}$ there is a phenomenon of overlapping of treatment traces, which probably limits the impact of the shape of the created section on the RSm parameter value. Figure 11a and 11b show the exemplary surface profiles after centrifugal burnishing and perpendicular shot peening.

The machining of centrifugal burnishing or perpendicular shot peening does not only impact the surface roughness parameters, shape of the profilogram, but also the shape of the AbbottFirestone curve. Figure 12 illustrates the exemplary curves after centrifugal burnishing (Fig. 12a) and after perpendicular shot peening (Fig. 12b). The Abbott-Firestone curve after shot peening is characterised by a greater inclination angle than after centrifugal burnishing, but significantly smaller than after milling. This means that the surface treated by perpendicular shot peening is characterised by less "flattened" vertices of micro-irregularities and a smaller material bearing ratio, which is confirmed by the measurement results of the surface roughness parameters.

The geometrical structure of $\mathrm{C} 45$ steel surface formed by centrifugal burnishing and perpendicular shot peening is different. The amplitude parameter Ra after centrifugal burnishing is from 1,1 to 1,7 times smaller with respect to the value after milling, while the surface roughness increase was achieved after perpendicular shot peening in relation to the value after the pre-treatment. A similar effect of the type of burnishing is noticeable for the height parameters $\mathrm{Rz}, \mathrm{Rp}, \mathrm{Rv}$. Exceptions include the treatment conditions for peening $\mathrm{E}_{\mathrm{z}}=160 \mathrm{~mJ}, \mathrm{x}_{\mathrm{s}}=0,15 \mathrm{~mm}$, for which the parameter Ra, Rz, Rp, Rv, Rk and Rpk values are decreased. The Rk and Rpk parameters after centrifugal burnishing have smaller values than after perpendicular shot peening.

For the surface machined by centrifugal burnishing within the range of applied machining parameters, the utility properties of the geometrical structure are improved with respect to the preceding machining.

Perpendicular shot peening causes "punching" of lubricant pockets with a greater depth on 
a)

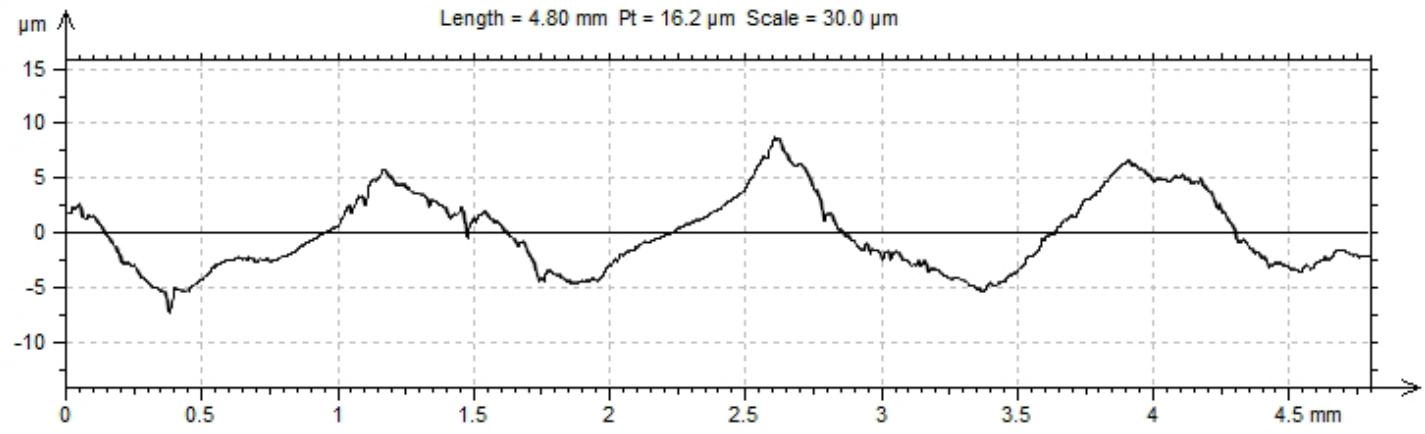

b)

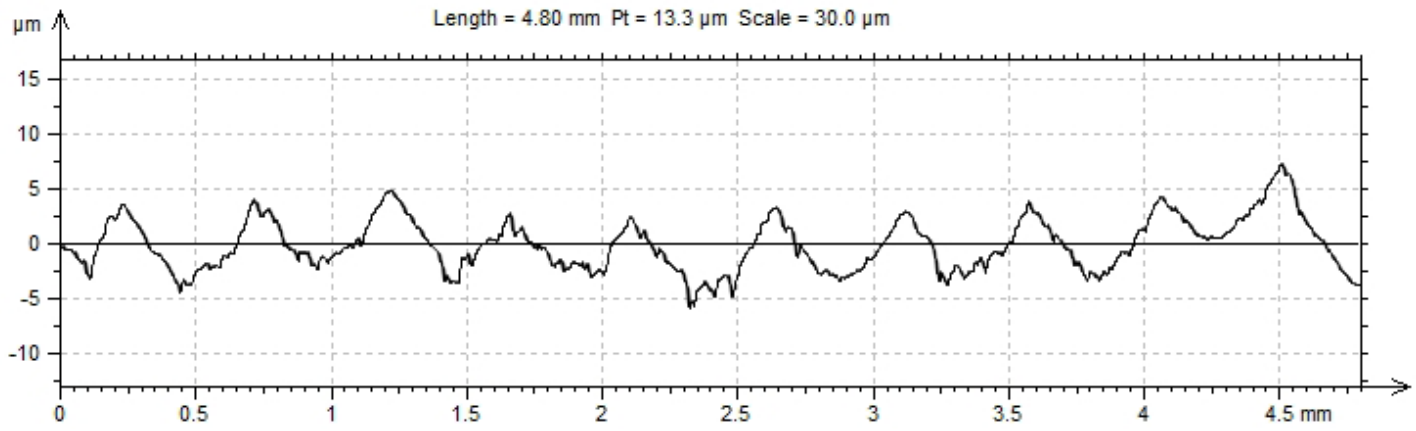

Fig. 11. Profilogram surface $C 45$ steel after: a) centrifugal burnishing - parameters $v_{g}=833 \mathrm{~m} / \mathrm{min}, v_{\mathrm{f}}=22734$ $\left.\mathrm{mm} / \mathrm{min}, \mathrm{f}_{\mathrm{p}}=0,5 \mathrm{~mm}(\mathrm{Ra}=0,82 \mu \mathrm{m}, \mathrm{Rz}=5,13 \mu \mathrm{m} \mathrm{RSm}=344 \mu \mathrm{m}), \mathrm{b}\right)$ perpendicular shot peening - parameters $\mathrm{E}_{\mathrm{z}}=160 \mathrm{~mJ}, \mathrm{x}_{\mathrm{s}}=0,5 \mathrm{~mm}(\mathrm{Ra}=1,44 \mu \mathrm{m} \mathrm{Rz}=7,88 \mu \mathrm{m} \mathrm{RSm}=282 \mu \mathrm{m})$

a)

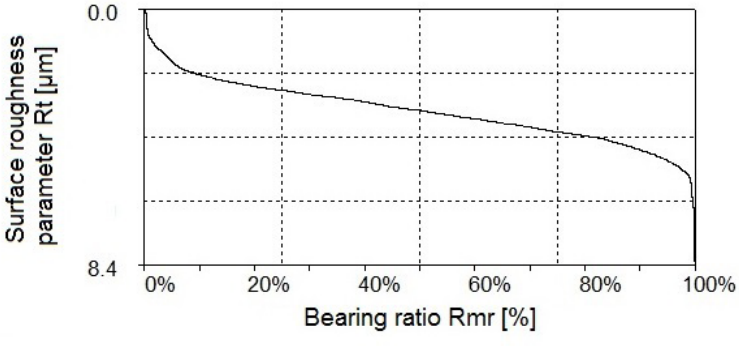

$\mathrm{Rpk}=1,15 \mu \mathrm{m} ; \mathrm{Rk}=2,8 \mu \mathrm{m} ; \mathrm{Rvk}=1,03 \mu \mathrm{m}$ b)

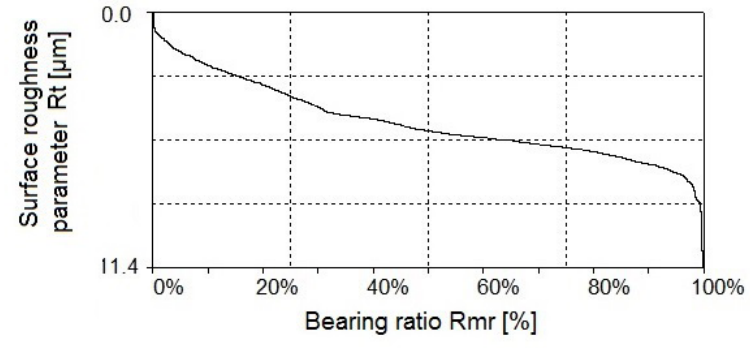

$\mathrm{Rpk}=1,93 \mu \mathrm{m} ; \mathrm{Rk}=4,26 \mu \mathrm{m} ; \mathrm{Rvk}=4,12 \mu \mathrm{m}$

Fig. 12. Abbott - Firestone'a curve after: a) centrifugal burnishing $\left(v_{g}=833 \mathrm{~m} / \mathrm{min}, v_{f}=22734 \mathrm{~mm} / \mathrm{min}, f_{p}=0,3\right.$ $\mathrm{mm}), \mathrm{b})$ perpendicular shot peening $\left(\mathrm{E}_{\mathrm{z}}=160 \mathrm{~mJ}, \mathrm{x}_{\mathrm{s}}=0,3 \mathrm{~mm}\right)$

the work surface. The Rvk parameter after peening is from $1,69 \mu \mathrm{m}$ to $2,59 \mu \mathrm{m}$, while after centrifugal burnishing $0,77 \div 1,29 \mu \mathrm{m}$.

The value of the gap formed between the traces on the treated surface is caused by the shape of the resulting impression.

\section{CONCLUSIONS}

The paper analysed the effect of the type of burnishing and technological parameters on the geometrical structure of $\mathrm{C} 45$ steel surface. The following conclusions summarize the results of the research conducted:
- perpendicular shot peening and centrifugal burnishing of C45 steel result in the reconstruction of the geometrical structure of the surface, shot peening and centrifugal burnishing cause the change of the shape of micro-irregularities,

- the increase of the impact energy during perpendicular shot peening results in the improvement of surface roughness in the range of $E_{z}=40 \mathrm{~m} \div 160 \mathrm{~mJ}$, for large $E_{z}$ the deterioration is noticeable, whereas using centrifugal burnishing the surface roughness parameters are increased with respect to the value after milling, 
- the increase of the distance between machining traces causes the raise in surface roughness for both types of burnishing,

- spherical processing traces are formed on the work surface as a result of perpendicular shot peening, the resulting impressions are elliptical after centrifugal burnishing,

- centrifugal burnishing causes the formation of micro-irregularities with intervals greater than after perpendicular shot peening,

- Abbott-Firestone curve is a degenerativeprogressive curve both for perpendicular shot peening and for cenrtrifgal burnishing.

\section{REFERENCES:}

1. Bagherifard S., Fernandez - Pariente I., Ghelichi R., Guagiliano M.: Effect of severe shot peening on microstructure and fatigue strength. International Journal of Fatigue, 65, 2014, 64-70.

2. Bagherifard S., Ghelichi R., Guagliano M.: Numerical and experimental analysis of surface roughness generated by shot peening. Applied Surface Science, 258, 2012, 6831-6840.

3. Bławucki S., Zaleski K.: The effect of the aluminium alloy surface roughness an the restitution coefficient. Advances in Science and Technology Research Journal, Vol. 9, 27, 2015, 66-71.

4. Burakowski T., Wierzchoń T.: Inżynieria powierzchni metali. Wydawnictwo Naukowo - Techniczne, Warszawa, 1995.

5. Galda L., Dzierwa A., Sep J., Pawlus P.: The effect of oil pockets shape and distribution on seizure resistance in lubricated sliding. Tribology Letters, 37, 2010, 301-311.

6. Galda L., Sep J., Prucnal S.: The effect of dimples geometry in the sliding surface on the tribological properties under starved lubrication conditions. Tribology International, 99, 2016, 77-84.

7. Harada Y., Fukaura K., Haga S.: Influence of microshot peening an surface layer characteristics of structural steel. Journal of Materials Processing Technology, 191, 2007, 297-301.

8. Korzyński M., Pacana A.: Centreless burnishing and influence of its parameters on machinig effects. Journal of Materials Processing Technology, 210, 2010, 1217-1223.
9. Kubit A., Bucior M., Zielecki W., Stachowicz F.: The impact of heat treatment and shot peening on the fatigue strength of 51CrV4 steel. Procedia Structural Integrity, 2, 2016, 3330-3336.

10. Kulakowska A., Kukielka L., Kukielka K., Malag L., Patyk R., Bohdal L.: Possibilty of steering of products surface layer properties in burnishing rolling process. Applied Mechanics and Materials, 474, 2014, 442-447.

11. Przybylski W.: Technologia obróbki nagniataniem. Wydawnictwo Naukowo - Techniczne, Warszawa, 1987.

12. Rudawska A., Reszka M., Warda M., Miturska I., Szabelski J., Stancekova D., Skoczylas A.: Milling as a method of surface pre-treatment of steel for adhesive bonding. Journal of Adhesion Science and Technology, 30, 23, 2016, 2619-2636.

13. Sandá A., García Navas V, Gonzalo O.: Surface state of Inconel 718 ultrasonic shot peened: Effect of processing time, material and quantity of shot balls and distance from radiating surface to sample. Materials and Design, 32, 2011, 2213-2220.

14. Skoczylas A., Zaleski K.: Studies on the selected properties of C45 steel elements surface layer after laser cutting, finishing milling and burnishing. Advances in Science and Technology Research Journal, Vol. 10, 32, 2016, 118-123.

15. Wieczorowski M., Cellary A., Chajda J.: Przewodnik po pomiarach nierówności powierzchni czyli o chropowatości i nie tylko. Zakład PoligraficznoWydawniczy M- Druk, Poznań, 2003.

16. Zaleski K.: Kształtowanie wybranych właściwości warstwy wierzchniej elementów metalowych w procesie nagniatania dynamicznego rozproszonego. Wydawnictwa Uczelniane Politechniki Lubelskiej, Lublin, 2008.

17. Zaleski K.: The effect of vibratory and rotational shot peening and wear on fatigue life of steel. Eksploatacja i Niezawodnosc Maintenance and Reliability, Vol. 19, 1, 2017, 102-107.

18. Zaleski R., Zaleski K., Gorgol M., Wiertel M.: Positron annihilation study of aluminum, titanium, and iron alloys surface after shot peening. Applied Physics A-Materials Science \& Processing, Vol. 120, No. 2, 2015, 551-559.

19. PN-EN ISO 13565 - 2 Struktura geometryczna powierzchni: metoda profilowa; powierzchnie o warstwowych właściwościach funkcjonalnych. 